\title{
Diagnóstico de neumonía adquirida en la comunidad en la población infantil
}

\author{
Dra. Luz Libia'
}

1 Neumóloga Pediatra, Hospital Universitario de Santander. Profesora Asociada, Universidad Industrial de Santander-Bucaramanga, Colombia.

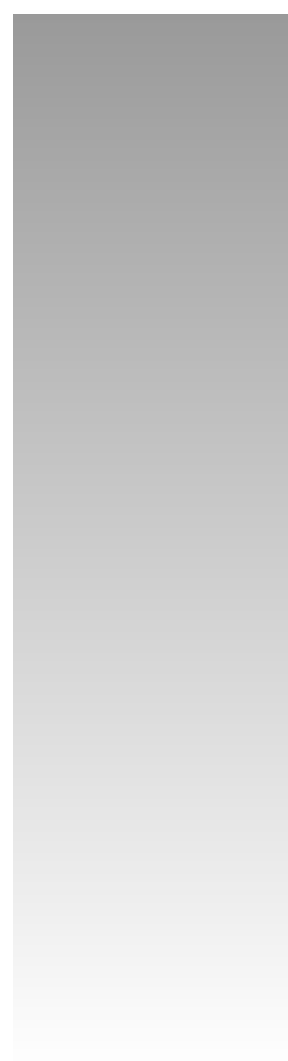

\section{DIAGNOSIS OF COMMUNITY-ACQUIRED PNEUMONIA IN CHILDREN POPULATION}

For the diagnosis of community-acquired pneumonia (CAP) in children, it is necessary to collect clinical, epidemiological, laboratory and imaging, mainly chest radiography. Diagnosis was based on laboratory tests that generate direct or indirect evidence of the agent responsible. Searching the causative agent is difficult, mainly due to the limitation to obtain appropriate samples and the difficulty in identifying the etiological agent and for differentiating between colonization and infection. With the methods currently available, it is estimated that a specific agent can detect between 16-85\% of cases, making it difficult to determine the true incidence of these infections, in addition, the variety of diagnostic techniques used in clinical studies and interpretation of the results in the absence of a germ isolation make it even more difficult to determine the actual incidence of the etiologic agents of CAP. We describe the different existing criteria for the recognition of CAP in children and weight of each in the approach to etiologic diagnosis.

Key words: Community-acquired pneumonia, diagnostic criteria, imaging, laboratory test, children.

\section{RESUMEN}

Para el diagnóstico de la neumonía adquirida en la comunidad (NAC) en la población infantil, es preciso reunir criterios clínicos, epidemiológicos, de laboratorio e imagenológicos, fundamentalmente la radiografia del tórax. El diagnóstico etiológico se apoya en pruebas de laboratorio que generan una evidencia directa o indirecta del agente responsable. La búsqueda del agente causal es difícil, debido principalmente a la limitación para obtener muestras adecuadas y a la dificultad para identificar el agente etiológico y para diferenciar entre colonización e infección. Con los métodos actualmente disponibles, se estima que se puede detectar un agente específico entre el 16-85\% de los casos, lo cual dificulta la determinación de la incidencia real de estas infecciones; además, la variedad de técnicas diagnósticas utilizadas en los estudios clínicos y la interpretación de los resultados en ausencia de aislamiento de un germen, hacen aún más difícil determinar la incidencia real de los agentes etiológicos de la NAC. Se describen los diferentes criterios existentes para el reconocimiento de la NAC en la población infantil y el peso de cada uno de ellos en la aproximación al diagnóstico etiológico.

Palabras clave: Neumonía adquirida en la comunidad, criterios diagnósticos, imagenología, laboratorio, niños.

\section{INTRODUCCIÓN}

Se denomina Neumonía Adquirida en la Comunidad (NAC), a la neumonía de etiología infecciosa que adquiere un individuo previamente sano, fuera de un hospital('). La neumonía sigue siendo una de las principales causas de mortalidad en la población pediátrica en todo el mundo. Según estimaciones de la Organización Mundial de la Salud (OMS), fallecen aproximadamente dos millones de niños cada año por esta causa, la gran mayoría de ellos, en los países en desarrollo(2). También es causa muy frecuente de morbilidad: El promedio

Correspondencia: Dra. Luz Libia Cala. Centro médico Carlos Ardilla Lulle, torre A, módulo 27. CRA 24 Nro I 54- 106 El Bosque Floridablanca-Colombia.

Teléfono fijo: 6383643-celular: 3002170139.

E-mail: Luzlibiacala@gmail.com

ISSN 07|8-332I Derechos reservados. de episodios de infección respiratoria al año, en niños menores de 5 años, es de 4 en quienes viven en zonas rurales, 8 en los que habitan en ciudades y hasta 12 si asisten a guarderías $^{(3)}$. Estas son razones, por demás suficientes para que, desde hace varios años se haya despertado un gran interés tanto por parte de la OMS como por la comunidad médica que maneja población pediátrica en todo el mundo, en desarrollar estrategias y guías encaminadas a realizar una detección precoz y tratamiento oportuno de esta enfermedad.

A pesar de lo anterior, el diagnóstico de un niño con una infección de vías aéreas inferiores (neumonía), sigue siendo un reto, pues no sólo las manifestaciones clínicas de las infecciones por virus, bacterias comunes o las denominadas atípicas pueden solaparse, sino que también, con cierta frecuencia coexisten. El diagnóstico etiológico de la NAC en el paciente pediátrico se apoya en pruebas de laboratorio que evidencian directa o indirectamente el germen responsable; 
llegar a la etiología precisa es difícil, debido principalmente a la limitación para obtener muestras adecuadas y a la dificultad para identificar el agente causal y para diferenciar entre colonización e infección ${ }^{(4,5)}$.

Se estima que con los métodos actualmente disponibles, se puede detectar un agente específico entre el 16 al 85\% de los casos, lo cual dificulta la determinación de la incidencia real de estas infecciones; además, la variedad de técnicas diagnósticas utilizadas en los estudios clínicos y la interpretación de los resultados en ausencia de aislamiento de un germen, hacen aún más difícil la determinación de la incidencia real de los agentes etiológicos de la NAC ${ }^{(1,6,7)}$.

\section{ENFOQUE DIAGNÓSTICO}

En el enfoque diagnóstico inicial de la NAC, es necesario ante todo, distinguir si el niño con infección respiratoria aguda, tiene compromiso respiratorio alto o bajo; si es bajo tratar de dilucidar al máximo si la neumonía es viral o es bacteriana (clásica o atípica), por las implicaciones terapéuticas que la diferenciación tiene. Para el acercamiento a dicha diferenciación se cuenta con parámetros clínicos, epidemiológicos, de laboratorio e imagenológicos, que analizados en conjunto, permitirán mejores resultados.

Desde el punto de vista clínico, un niño con infección respiratoria aguda alta puede cursar con tos, rinorrea, obstrucción nasal, coriza, fiebre, odinofagia y mayor o menor compromiso del estado general. El mismo complejo sintomático puede observarse en un niño con neumonía, pero la caracterización de la extensión de la infección al tracto respiratorio inferior, está dada por la presencia además de otros signos como la taquipnea, estertores, tiraje subcostal, apariencia clínica de que "no luce bien", dolor torácico e incluso en algunos casos dolor abdominal.

La taquipnea, como signo único ha demostrado ser el mejor predictor de neumonía, comprobada por radiografía, en niños menores de cinco años. Tiene sensibilidad de 74\% y especificidad de $67 \%$, según estudios de la $\mathrm{OMS}^{(8)}$, pero es menos sensible y específica en los primeros tres días de la enfermedad. Se considera taquipnea, una cifra mayor de 60 por min en el niño menor de dos meses, mayor de 50 por min en niño de 2 a I I meses y mayor de 40 por minuto entre los 12 meses y los 5 años ${ }^{(9)}$. Otros trabajos han demostrado también una alta correlación entre taquipnea e hipoxemia: una frecuencia respiratoria mayor de 70 por min en menores de un año, tuvo una sensibilidad de $63 \%$ y una especificidad de $89 \%$ para demostrar hipoxemia, medida por oximetría de pulso ${ }^{(10)}$. Vale la pena tener presente, como lo mencionan Jadavji y cols, en su guía para el diagnóstico y tratamiento de la neumonía en pediatría, que la taquipnea puede faltar en un niño con retracciones severas $u$ otros signos de aumento del trabajo respiratorio(II). Así como la taquipnea es el mejor indicador de infección respiratoria baja, el tiraje subcostal lo es de gravedad en neumonía. En el niño menor de dos meses, para que mantenga el valor de gravedad, el tiraje debe ser intenso, puesto que la mayor maleabilidad y distensibilidad de la caja torácica en este grupo de edad, permite que con la respiración normal los niños tengan ligero tiraje subcostal.
Son signos de máxima gravedad, o predictivos de muerte por neumonía: la cianosis, la incapacidad de ingerir líquidos, el quejido espiratorio, el aleteo nasal, las radiografías de tórax con cambios severos y la ausencia de fiebre en niños desnutridos severos ${ }^{(12-14)}$. El examen físico de un niño con neumonía puede revelar otros hallazgos como la disminución del murmullo vesicular en el lado afectado, estertores que no se modifican con la tos ni las maniobras de higiene bronquial; un niño con mayor compromiso, puede tener soplo tubárico, aumento de la transmisión de vibraciones vocales, pectoriloquia áfona y broncofonía, signos estos que constituyen el síndrome clásico de consolidación pulmonar. Una postura antálgica, dolor a la inspiración, matidez a la percusión junto a disminución de las vibraciones vocales y ausencia de murmullo vesicular en el lado afectado, hallazgos clásicos del síndrome de derrame pleural, pueden encontrarse en niños que cursan con derrame paraneumónico o neumonía complicada con empiema. No son despreciables los casos de niños menores de 5 años que manifiestan sus neumonías con dolor abdominal como signo cardinal de la enfermedad ${ }^{(15,16)}$.

\section{NEUMONÍA O BRONQUIOLITIS}

La neumonía y la bronquiolitis son las dos infecciones respiratorias bajas más frecuentes. Se debe considerar en primera instancia la posibilidad de bronquiolitis, si se trata de un niño menor de dos años con un primer episodio bronco-obstructivo, precedido por infección respiratoria aguda alta, dos o tres días antes, asociado a taquipnea o cualquier otro signo de dificultad respiratoria, aún más si se presenta en época de epidemia (en Colombia temporada de lluvias)(4).

\section{NEUMONÍA BACTERIANA O VIRAL}

Como se vio en párrafos anteriores, es un reto para el médico reconocer la neumonía en un paciente, pero lo es aún más la diferenciación entre la etiología viral o bacteriana. Para acercarse a esta diferenciación, debe apoyarse en una suma de criterios, tanto clínicos, epidemiológicos, de laboratorio e imagenológicos (fundamentalmente radiológicos), teniendo en cuenta la disposición que de ellos tenga y la justificación de acuerdo al grado de severidad del caso.

\section{CRITERIOS CLÍNICOS Y EPIDEMIOLÓGICOS}

No hay criterios clínicos que aisladamente sean capaces de diferenciar la etiología viral de la bacteriana, entre otras cosas porque hay una proporción importante de pacientes que tienen neumonías mixtas, (entre 8-23\% según distintas series) $(1,6,7,17)$. Sin embargo, algunos signos o síntomas sugerirían más una u otra causa, como lo muestra Macintosh en su trabajo(18), donde la conjuntivitis y la otitis media se encontraron en el $27 \%$ y $42 \%$ respectivamente, de los pacientes con neumonía bacteriana y sólo la presentaban en su orden, el $8 \%$ y $22 \%$ de los niños con neumonías virales. Si bien es cierto que las sibilancias se encuentran acompañando al 43-56\% de los 
pacientes con neumonías virales, el 16\% de los pacientes con pneumoniae y Clamydia trachomatis las presentan ${ }^{(18)}$; otros signos como el dolor torácico, las artralgias y la cefalea acompañando a las sibilancias, podrían sugerir ampliamente infección por Mycoplasma. Signos como fiebre mayor de 39 grados centígrados, apariencia tóxica, dolor pleurítico y persistencia de síntomas respiratorios por varios días, han sido relacionados por algunos autores con enfermedad invasiva y es bien conocido que son más invasivas las bacterias que los virus $^{(18-20)}$

La edad, junto con el estado de inmunización del paciente y la noción de contagio, son los factores epidemiológicos que mejor permite relacionar la neumonía con el agente causal más probable. Por otra parte, la asistencia a guarderías debe hacer pensar más en causa viral y por el contrario, el antecedente de hospitalización reciente, es un factor de riesgo para infección por estafilococo meticilino-resistente. Los virus exhiben brotes de infección estacionales, sobre todo a finales de otoño y durante el invierno y en los países tropicales durante las épocas de lluvia; las bacterias exhiben menos fluctuaciones estacionales.

\section{PRUEBAS DE LABORATORIO}

Al igual que sucede con los criterios clínicos, no existen pruebas de laboratorio que aisladamente determinen si una neumonía es viral o bacteriana; la indicación de realizarlas está basada fundamentalmente en su disponibilidad, acceso y factibilidad, más que estrictamente en la evidencia. Así las cosas, las pruebas específicas para identificar cada agente, sólo deben realizarse si contribuyen a modificar el tratamiento(4).

Los reactantes de fase aguda o marcadores inespecíficos de inflamación: Recuento de leucocitos, velocidad de sedimentación globular (VSG), proteína C reactiva (PCR), las interleuquinas (IL) y la procalcitonina (PCT) son de utilidad limitada, cada uno como dato aislado, pero su utilización en conjunto, ofrece más ayuda para una aproximación diagnóstica.

\section{Recuento de leucocitos}

Comúnmente se ha establecido que recuento de leucocitos $>15.000 / \mathrm{mm}^{3}$ y desviación a la izquierda, sugieren una etiología bacteriana de la neumonía; sin embargo, estos hallazgos no son específicos y pueden presentarse también en las neumonías por Mycoplasma pneumoniae o víricas; por el contrario, pueden faltar en algunas neumonías bacterianas ${ }^{(21-23)}$. El número de neutrófilos como marcador de infección bacteriana tiene una especificidad discreta y sólo valores por encima de $10.000 / \mathrm{mm}^{3}$, bandas mayores o iguales al $5 \%$ permitirían una cierta predicción ${ }^{(24)}$ de infección bacteriana.

\section{Velocidad de sedimentación globular}

No es un buen marcador de infección aguda, por su lento ascenso y por su baja sensibilidad y especificidad para diferenciar entre etiología bacteriana y viral. Sólo niveles por encima de 100 mm tienen utilidad como marcador de infección bacteriana. Su lenta elevación y descenso invalidan este parámetro como reactante de fase aguda con poder discriminatorio(25).

\section{Proteína $\mathbf{C}$ reactiva}

Aunque está elevada en un gran número de procesos inflamatorios/infecciosos, su utilidad en el diagnóstico etiológico de la NAC es limitado. Aunque la PCR no está indicada de forma rutinaria en el manejo de las NAC no complicadas, una cifra superior a $80 \mathrm{mg} / \mathrm{l}$ podría orientar hacia una etiología bacteriana; sin embargo, en una revisión sistemática en 2005, van der Meer encuentra que la PCR no tiene suficiente especificidad y sensibilidad como para orientar la etiología de la infección respiratoria(25-27).

\section{Procalcitonina}

En estudios realizados en población infantil se ha observado que la elevación de la PCT se relaciona con etiología bacteriana de la NAC, el valor encontrado en individuos sanos es $<0$, I ng/ml. Valores iguales o superiores a I $\mathrm{ng} / \mathrm{ml}$ se han asociado a neumonía bacteriana y por encima de $2 \mathrm{ng} /$ $\mathrm{ml}$, específicamente con neumonía por neumococo, con un elevado valor predictivo y especificidad (80\%), mientras que niveles inferiores a $0,5 \mathrm{ng} / \mathrm{ml}$ orientan hacia una neumonía de etiología no bacteriana(28-31).

\section{Interleuquina 6}

Aunque esta citoquina ha sido asociada con el aumento de los leucocitos, niveles elevados de procalcitonina y consolidación en la radiografía de tórax; no ha habido ninguna correlación con la etiología de la NAC. Su medición no se encuentra disponible en la mayoría de los centros hospitalarios, por lo cual no se recomienda su uso ${ }^{(25,32)}$.

En conclusión, los 4 marcadores no específicos de inflamación: Recuento de leucocitos, velocidad de sedimentación globular, proteína C reactiva y procalcitonina, tienen un papel limitado en la diferenciación entre etiología bacteriana o viral, en la NAC en niños, si se utilizan de forma aislada; sin embargo, si la mayoría de estos marcadores se encuentran elevados, la etiología bacteriana es mucho más probable. En la práctica diaria, estos valores deben siempre interpretarse junto con otras observaciones, como historia clínica, hallazgos al examen físico y en la radiografía del tórax ${ }^{(25,30)}$.

Las pruebas microbiológicas buscan aislar e identificar el agente etiológico de NAC, pero su baja sensibilidad, la dificultad en obtener una muestra adecuada y la escasa relación costo/beneficio, hacen que en la actualidad no se recomiende realizar estudios microbiológicos de forma rutinaria a los niños diagnosticados con NAC de manejo ambulatorio. Por el contrario, en los niños que requieren ser hospitalizados o en quienes se presente alguna complicación, es importante realizar estos estudios para intentar llegar a establecer su etiología ${ }^{(25)}$. Para ello se dispone de las siguientes pruebas bacteriológicas:

\section{Hemocultivo}

El rendimiento de esta prueba es muy bajo, dado que la neumonía no siempre cursa con bacteriemia; dependiendo del agente implicado, la positividad del hemocultivo en NAC puede llegar a ser menor del $10 \%(25)$. Se recomienda su realización en pacientes con evolución tórpida, en formas graves de neumonía, con sospecha del agente resistente o neumonías con formas inusuales. Su utilidad disminuye cuando el paciente ha recibido antibióticos ${ }^{(4)}$. 


\section{Cultivo bacteriano de secreción nasofaríngea-cultivo de esputo}

El cultivo de secreción nansofaríngea no proporciona ninguna información, ya que la presencia de bacterias en la nasofaringe no es indicativa de infección de la vía aérea inferior, a menos que se trate de un paciente con fibrosis quística, en quienes la microbiota a este nivel, se relaciona con los microorganismos encontrados en el sistema respiratorio bajo ${ }^{(25)}$. La misma interpretación merece el cultivo de esputo en niños, puesto que la mayoría de muestras en estos pacientes corresponden a saliva, teniendo en cuenta que la capacidad de expectorar de los niños es muy baja. Sólo deberían procesarse muestras que contengan menos de 10 células epiteliales por campo y más de 25 polimorfonucleares. Es una técnica de baja sensibilidad y especificidad ${ }^{(33)}$.

\section{Punción pulmonar}

Es un método sensible con alto rendimiento diagnóstico, con positividad hasta de $79 \%$, pero debido a sus riesgos e implicaciones éticas, no se realiza de rutina; sólo es aceptable realizarla en pacientes con neumonía con grave afectación del estado general, con riesgo de morir y sin diagnóstico causal, bajo estrictos parámetros de indicación (presencia de consolidación) e idoneidad del médico(34).

\section{Detección de antígenos bacterianos}

La detección de antígenos bacterianos en orina puede ser útil como predictor negativo de infección, principalmente en caso de $S$. pneumoniae en el niño mayor. En muchos pacientes pierde utilidad en el diagnóstico debido a que el resultado puede ser positivo en portadores y en los que han recibido recientemente vacunación antineumocóccica. La detección de antígeno neumocóccico en líquido pleural tiene, en algunos estudios, una sensibilidad y una especificidad mayor del $90 \%{ }^{(5,35)}$. La sensibilidad y especificidad para antígenos de Haemophilus influenzae tipo B en suero y orina es de aproximadamente $90 \%$. Al igual que con S. Pneumoniae, puede haber falsos positivos cuando existen otros focos infecciosos causados por Haemophilus influenzae tipo B o cuando el niño ha recibido vacuna conjugada específica contra esta bacteria(4). La detección de antígeno soluble de Legionella en orina tiene una sensibilidad del 60 al $90 \%$ y especificidad del $99 \%$; está indicada en brotes epidémicos o en neumonías graves ${ }^{(25)}$.

\section{Detección de antígenos virales respiratorios}

El enzimoinmunoanálisis (EIA) es la base de las pruebas rápidas para el diagnóstico de gripe y de virus respiratorio sincitial (VRS), con una sensibilidad entre el 60 y el $80 \%$, y una especificidad mayor a $90 \%$. Se basan en la utilización de anticuerpos monoclonales dirigidos frente a distintos antígenos virales, detectando los virus no viables presentes en la muestra. Las pruebas de inmunofluorescencia (IF) permiten obtener resultados rápidos, aunque su principal limitante es que requiere un microscopio de fluorescencia y personal entrenado en la observación de este tipo de preparaciones ${ }^{(36)}$.

\section{Técnicas moleculares de diagnóstico rápido}

Estas técnicas han permitido revaluar el papel de los virus respiratorios como agentes causales de NAC en el niño. Se destacan por su sencillez y versatilidad; las pruebas de PCR multiplex o las basadas en microchips arrays, pueden llegar a identificar más de 10 patógenos virales en pocas horas, incrementando significativamente la sensibilidad del diagnóstico microbiológico en muestras de sangre o líquido pleural. En el caso de bacterias como S. pneumoniae, diferencian los distintos serotipos implicados en el desarrollo de la enferme$\operatorname{dad}^{(37,38)}$.

\section{Métodos serológicos}

El diagnóstico serológico de los virus respiratorios necesita generalmente el análisis de sueros pareados (extracción de dos muestras de suero), la primera en la fase aguda de la enfermedad y la segunda en la fase de convalecencia. Esto representa una gran dificultad, ya que muchos de los virus respiratorios además de ser muy prevalentes, producen reinfecciones, por lo que en muchos casos no se podrá demostrar una verdadera seroconversión ni un aumento significativo de los títulos de anticuerpos. Su mayor utilidad se da en los estudios seroepidemiológicos ${ }^{(25)}$.

Aunque se han desarrollado técnicas basadas en la reacción en cadena de la polimerasa (PCR), el diagnóstico serológico por técnicas de ELISA sigue siendo fundamental, en el caso de las infecciones por bacterias atípicas ( $M$. pneumoniae, $C$. pneumoniae, C. burnetti y L. pneumophila). En el caso de M. pneumoniae la principal limitación del estudio serológico radica en que en la reinfección no hay respuesta de IgM, sino una rápida elevación de IgG y que además, la lgM puede persistir elevada durante meses o años, de modo que en el niño o en el adulto joven, la detección de lgM puede no corresponder a una infección reciente ${ }^{(39)}$. En el caso de las dos especies del nuevo género Chlamydophila, compuesto por C. pneumoniae y C. psittaci, la microinmunofluorescencia es la única técnica recomendada en la actualidad para su diagnóstico sistemático ${ }^{(40)}$.

\section{EVALUACIÓN RADIOLÓGICA}

La radiografía de tórax es un elemento de gran ayuda para la confirmación del diagnóstico de neumonía, pero no es un criterio de certeza. Los dos patrones descritos que predominan en neumonía son el alveolar y el intersticial. Por el contrario, su utilidad para una clara diferenciación entre neumonía viral y bacteriana está muy cuestionada. En un meta-análisis de 13 estudios relevantes encontrados en la literatura con diagnóstico etiológico comprobado de neumonía, se escogieron 5 que cumplieron a cabalidad todos los criterios de inclusión exigidos para el meta-análisis. La radiografía del tórax no mostró precisión para diferenciar neumonía viral de bacteriana(4). En esta revisión sistemática, el autor recomienda tomar con precaución los resultados porque los estándares de referencia para diagnóstico etiológico son poco reproducibles ya que fueron diferentes en cada uno de los trabajos (detección de antígenos en sangre o en orina, detección ascendente de anticuerpos a una bacteria específica, hemocultivos o cultivo de efusión pleural, cultivo de bacterias de lavado broncoalveolar, punción pulmonar o biopsia).

Se han descrito como signos clásicos de neumonía bac- 
teriana: los infiltrados alveolares en parche o consolidación lobar (al menos en la mitad de los pacientes) o de distribución subsegmentaria, pero estos también se pueden encontrar en neumonías virales y atípicas. La presencia de consolidación lobar o segmentaria, neumatoceles y el abceso pulmonar están significativamente asociadas con infección bacteriana ${ }^{(42,43)}$.

A pesar de lo ya mencionado, muchos casos de neumonía bacteriana no se acompañan del clásico patrón radiográfico descrito antes para este tipo de neumonías, especialmente en la etapa temprana de la enfermedad y esporádicamente algunos virus pueden presentar patrones radiológicos de consolidación (adenovirus, por ejemplo) lo cual hace aún mucho más difícil en la práctica el diagnóstico etiológico. En un estudio de 215 niños con NAC y con diagnóstico etiológico confirmado, de los cuales 132 tenían etiología bacteriana y 8 I exclusivamente viral, los autores encontraron que los infiltrados alveolares tenían una sensibilidad de $72 \%$ y una especificidad de $51 \%$, para identificar la etiología bacteriana, lo cual era estadísticamente significativo; la especificidad aumentaba al $85 \%$ cuando los infiltrados alveolares eran de tipo lobar, principalmente en los menores de dos años. Los infiltrados intersticiales en cambio, no lograron diferenciar adecuadamente entre neumonía viral y bacteriana; la hiperaireación, las atelectasias y la efusión pleural pequeña, tampoco tuvieron significancia alguna para esta diferenciación $n^{(24,30)}$.

Hace varios años, Khamapirab y Glezen describieron un puntaje para diferenciar neumonía bacteriana de viral, en la radiografía del tórax, que sin ser de alta especificidad, sí orienta de manera práctica sobre la posible causa (Tabla I) ${ }^{(44)}$. Más recientemente en Argentina, se ideó y validó un puntaje predictor de neumonía bacteriana, adicionando a los criterios radiológicos descritos por Kamapirad y Glezen, algunos parámetros clínicos y paraclínicos usualmente presentes en este tipo de neumonía (temperatura axilar mayor o igual a $39^{\circ} \mathrm{C}$, edad mayor o igual a 9 meses, neutrófilos absolutos mayores o iguales a $8.000 / \mathrm{mm}^{3}$, bandas mayores o iguales a $\left.5 \%\right)$. Un valor mayor o igual a 4 de este puntaje se asocia a neumonía bacteriana con una sensibilidad de $100 \%$ y una especificidad de $93,7 \%$; valor predictivo positivo de $75,9 \%$ y predictivo negativo de 100\% (Tabla 2). En el grupo de pacientes en quienes se hizo la validación, los datos se reprodujeron en forma similar: sensibilidad de $100 \%$, especificidad de 93,7\%; valor predictivo positivo de $85,7 \%$ y negativo de $100 \%(19)$.

Existen varios estudios de casos que describen los hallazgos radiológicos en neumonías por Mycoplasma, virus, Chlamydia y Streptococcus pneumoniae; sin embargo, ningún hallazgo es útil para hacer una diferenciación clara. El Mycoplasma pneumoniae muestra patrones radiológicos variables e inespecíficos, siendo el patrón intersticial (reticular o peribronquial), el más frecuentemente encontrado; ocasionalmente se presentan consolidaciones. El compromiso puede ser bilateral o unilateral (más frecuente), de predominio basal, con atelectasias lineales, adenopatías hiliares (33\%); el derrame pleural no es común (20\%) y si existe es pequeño y no progresivo; característicamente los hallazgos se correlacionan poco con la clínica ${ }^{(4)}$ (Figura I).

En Chlamydia hay signos de atrapamiento y compromiso intersticial difuso bilateral, con infiltración peribronquial y microatelectasias (Figuras 2 y 3).

En la neumonía complicada los hallazgos más frecuentes son el deterioro radiográfico con la presencia de efusión pleural e imágenes hiperlúcidas como neumoatoceles, neumotórax, absceso, loculaciones con o sin niveles hidroaéreos y sugieren fuertemente neumonía bacteriana por Staphylococcus aureus o Streptococcus pneumoniae. Menos frecuentemente Haemophilus influenzae. En la neumonía por Staphylococcus aureus los hallazgos más relevantes son:

- Presencia de consolidación lobar, cavitación y neumotórax con una tendencia al deterioro radiográfico después de la admisión.

Tabla I. Puntaje para diferenciación de neumonía bacteriana y viral en la radiografía del tórax

\begin{tabular}{|c|c|c|}
\hline Característica & Bacteriana & Viral \\
\hline $\begin{array}{l}\text { Infiltrados } \\
\text { Lobares, lobulares, segmentarios, subsegmentarios bien definidos } \\
\text { Parches menos bien definidos } \\
\text { Intersticiales, peri-bronquiales, pobremente definidos }\end{array}$ & $\begin{array}{l}+2 \\
+1\end{array}$ & -1 \\
\hline $\begin{array}{l}\text { Localización } \\
\text { Lóbulo único } \\
\text { Múltiples lóbulos, bien definidos } \\
\text { Múltiples sitios, parahiliares pobremente definidos }\end{array}$ & $\begin{array}{l}+1 \\
+1\end{array}$ & -1 \\
\hline $\begin{array}{l}\text { Líquido en el espacio pleural } \\
\text { Líquido evidente } \\
\text { Disminución mínima del espacio }\end{array}$ & $\begin{array}{l}+2 \\
+1\end{array}$ & \\
\hline $\begin{array}{l}\text { Absceso o neumatocele } \\
\text { Bien definido } \\
\text { Mal definido }\end{array}$ & $\begin{array}{l}+2 \\
+1\end{array}$ & \\
\hline $\begin{array}{l}\text { Atelectasia subsegmentaria, usualmente en múltiples sitios } \\
\text { Compromiso del lóbulo medio o de los lóbulos superiores }\end{array}$ & & $\begin{array}{l}-1 \\
-1\end{array}$ \\
\hline
\end{tabular}

Puntajes promedio de $+4,5$ se relacionan con neumonías bacterianas y los puntajes promedio menores o iguales a I, 9 con neumonías virales ${ }^{(44)}$. 
Tabla 2. Puntaje predictor de neumonía bacteriana (PPNB)

\begin{tabular}{|lc|}
\hline Variable & Puntos \\
Temperatura axilar $\geq 39^{\circ} \mathrm{C}$ & 3 \\
Edad $\geq 9$ meses & 2 \\
Neutrófilos absolutos $\geq 8.000 / \mathrm{mm}^{3}$ & 2 PPNB $\geq 4$ \\
Bandas $\geq 5 \%$ & । \\
Rx según "score" Khamapirad & -3 a 7 \\
Puntaje total posible & Hasta I5 \\
\hline
\end{tabular}

Adaptada de: Moreno LO, Krishnan JE, Duran P y Ferrero F. Development and Validation of a Clinical Prediction Rule to Distinguish Bacterial From Viral Pneumonia in Children. Pediatr Pulmonol 2006; 41 : 331 -7.

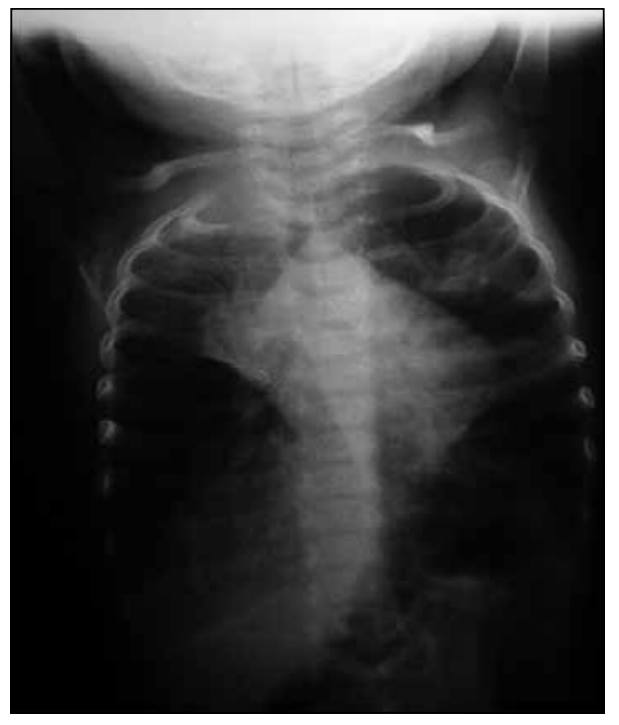

Figura 2. Neumonía por Chalamydia trachomatis en niño de 3 meses.

- Neumatoceles en el $41 \%$ de los casos.

- Neumotórax en el $20 \%$.

- Efusión pleural en una tercera parte.

- Opacidad en parches bilateral en el 35\%(45).

El líquido, si es libre, se moviliza fácilmente y se detecta con los cambios de posición, tomando una radiografía de tórax en decúbito lateral sobre el lado sano(46). Son sugestivas de empiemas complicados, las imágenes de loculaciones con o sin niveles hidroaéreos o las colecciones laterales o posteriores; engrosamiento de la pleura y la formación de trabeculaciones ${ }^{(46)}$. Cuando la cantidad de líquido es muy pequeña puede ser necesario otro método diagnóstico como la ecografía de tórax y cavidad pleural, pero el rendimiento diagnóstico depende del examinador. Este también es el método diagnóstico ideal para detectar derrames tabicados ${ }^{(47-49)}$ (Figuras 4 y 5).

La existencia de un nivel hidroaéreo en la placa de tórax

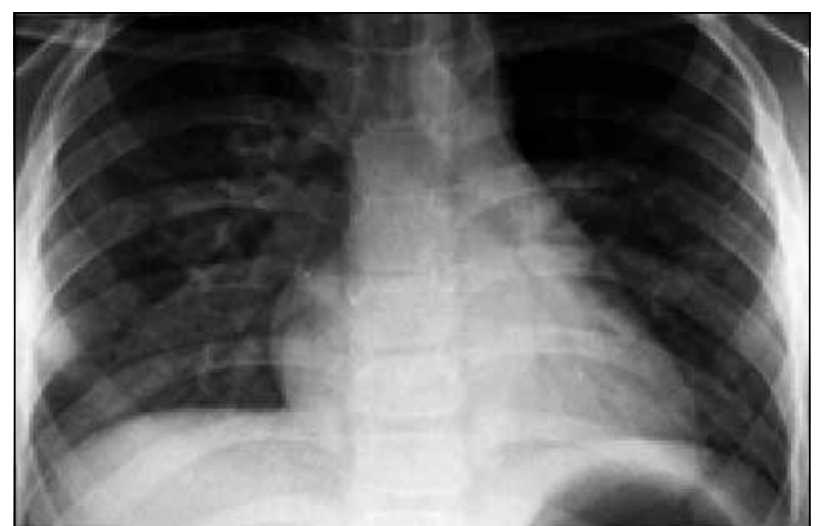

Figura I. Neumonía por Mycoplasma pneumoniae. Obsérvense infiltrados intersticiales reticulares y peribronquiales de predominio basal.

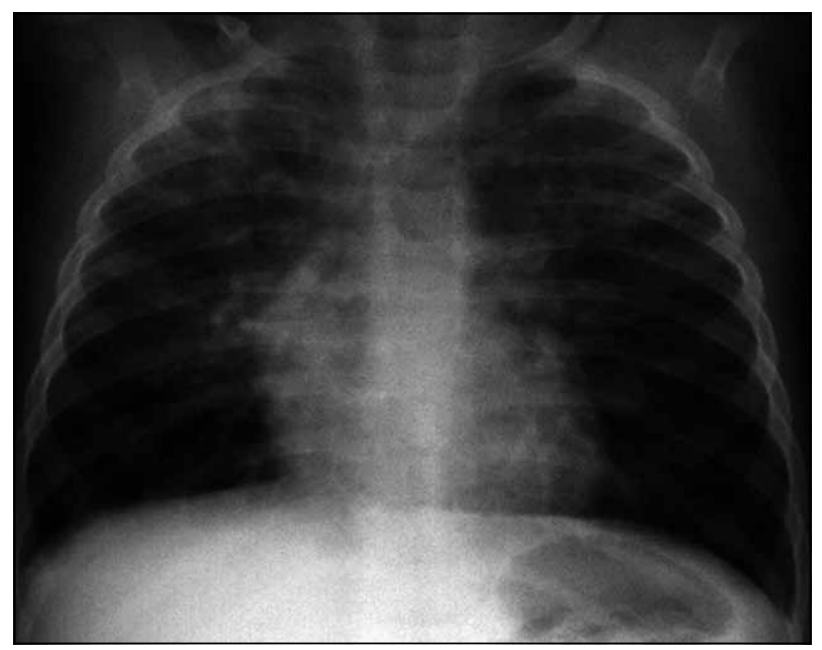

Figura 3. Neumonía por Chlamydia trachomatis en niña de 30 días. Obsérvese gran atrapamiento aéreo y atelectasias múltiples.

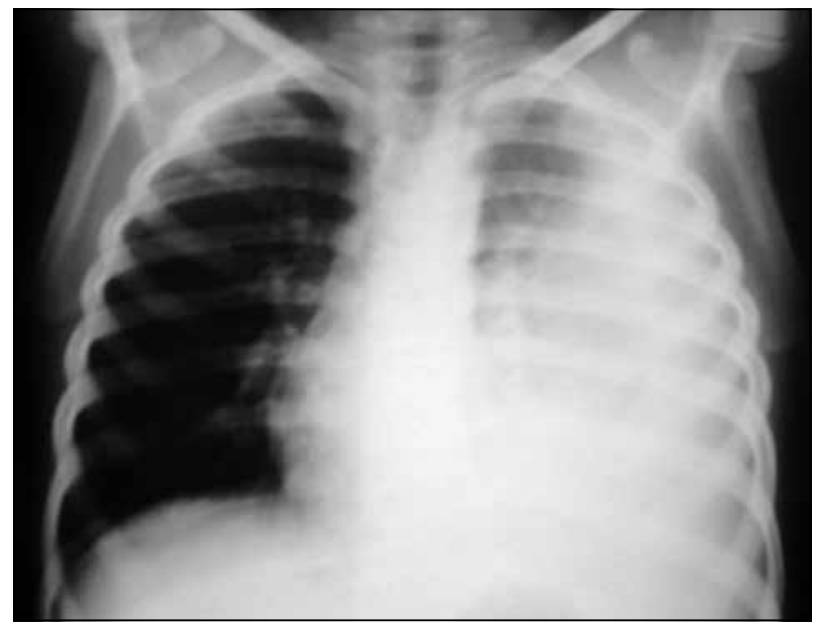

Figura 4. Neumonía con empiema tabicado. Por Streptococcus pneumoniae. 


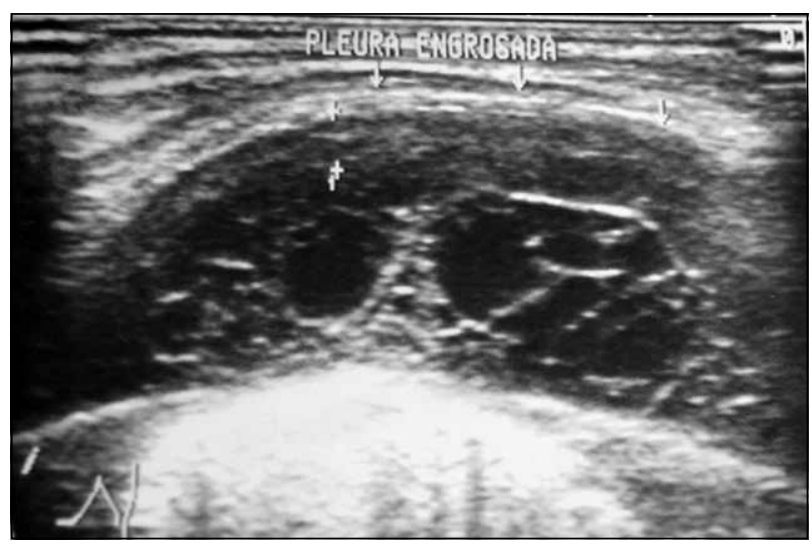

Figura 5. Ecografías del mismo paciente evidenciando tabiques en cavidad pleural.

indica la presencia de una fístula broncopleural, neumotórax acompañante, presencia de bacterias formadoras de gas o la ruptura del esófago ${ }^{(47)}$. Por lo anteriormente descrito, las distintas guías recomiendan realizar radiografía de tórax en pacientes:

- Que ameriten hospitalización (tienen neumonía grave).

- Con sospecha de complicaciones.

- Menores de 36 meses, con fiebre mayor de $39^{\circ} \mathrm{C}$ y foco oculto.

- Con evolución tórpida y/o evidencia de complicaciones.

No es necesario realizarla en pacientes con diagnóstico de neumonía, según la OMS, es decir, sin tiraje ${ }^{(1,4,20)}$.

\section{CONCLUSIONES}

Una vez hecha la revisión de este capítulo, es claro que el diagnóstico etiológico de la neumonía en los niños es difícil y que en la práctica, un criterio aislado, sea clínico, epidemiológico, de laboratorio o imagenológico, no es capaz de diferenciar neumonía bacteriana de viral o atípica. Sólo la combinación de varios de ellos, hacen la mejor aproximación; por tanto, el médico clínico debe esmerarse en reunir varios de estos criterios, de acuerdo a su disponibilidad y acceso, para optimizar el diagnóstico y manejo del paciente.

\section{REFERENCIAS}

I. Bradley JS, Byington CL, Shah SS, et al. The management of community-acquired pneumonia in infants and children older than 3 months of age: clinical practice guidelines by the Pediatric Infectious Diseases Society and the Infectious Diseases Society of America. Clin Infect Dis 201 I; 53: e25.

2. Reducción de la mortalidad en la niñez. Organización Mundial de la Salud, centro de prensa. Nota descriptiva número 178, septiembre 2012.

3. Lozano JM. Epidemiología de las enfermedades repiratorias en la niñez. Neumología Pediátrica. Infección, alergia y enfermedades respiratorias en el niño. Reyes MA, Aristizábal G, Leal FJ. 5 Edición.
Editorial Médica Panamericana. Bogotá; 2006.

4. Agudelo B, Arango M, Cala LL, et al. Asociación Colombiana de Neumología Pediátrica. Guía de práctica clínica en el tratamiento del niño con neumonía adquirida en la comunidad 20 I0; 5: 7-102.

5. Navarro D, García-Maset L, Gimeno C, Escribano A, Garcíade-Lomas J. Performance of the Binax NOW Streptococcus pneumoniae urinary antigen assay for diagnosis of pneumonia in children with underlying pulmonary diseases in the absence of acute pneumococcal infection. J Clin Microbiol 2004; 42: 4853-5.

6. Lee PI, Chiu CH, Chen PY, Lee CY, Lin TY. Guidelines for de management of comunity -acquired pneumoniae in children. Acta Paedriatr Taiwan 20007; 48: 167-80.

7. Isaacs, D. Problems in determining the etiology of communityacquired childhood pneumonia. Pediatr Infect Dis J 1989; 8: 143-6.

8. Programme for the control of Acute Respiratory Infections. Technical bases for the WHO recommendations on the management of pneumonia in children at first-level health facilities. Geneva: World Health Organization, 1991. WHO/ARI91.20.

9. Palafox M, Guiscafre $H$, Reyes $H$, et al. Diagnostic value of tachypnoea in pneumonia defined radiologically. Arch Dis Child 2000; 82: 41 e5.

10. Smyth $A$, Carty $H$, Hart CA. Clinical predictors of hipoxaemia in children with pneumonia. Ann Trop Paediatr 1998; 18: 31-40.

1।. Jadavji T, Law B, Lebel MH, Kennedy WA, et al. A. practical guide for the diagnosis and treatment of pediatric pneumonia. CMAJ 1997; 156: S703-S7| I.

12. Shann F, Barrer J, Poore P. Clinical signs that predict death in children with severe pneumonia. Pediatr Infect Dis J 1989, 8: 8525.

13. Spooner V, Barrer J, Tulloch J, et al. Clinical signs and risk factors associated with pneumonia in children admitted to Goroka Hosiptal, Papua, New Guinea. J Trop Pediatr 1989; 35: 295-300.

14. Zukin DD, Hofman JR, Cleveland RH, et al. Correlation of pulmonary signs and symptoms with chest radiographs in the pediatric age group. Ann Emerg Med 1986; 15: 792-6.

15. Ruvinsky R. Balanzt AM. Neumonías bacterianas y virales. En: Infecciones respiratorias en niños. Washington DC. Organización Panamericana de la Salud-Organización Mundial de la Salud 1997 : 215-49.

16. Bachur R, Perry H, Harper MB. Occult pneumonias: empiric chest radiographs in febrile children with leukocytosis. Ann Emerg Med I 199; 33: 166-73.

17. Padilla Ygreda JLPF, Rojas Galarza R, Tantaleán Da Fieno J, Suárez Moreno V, Cabezas Sánchez C, et al. Perfil etiológico de la neumonía adquirida en la comunidad en niños de 2 a 59 meses en dos zonas ecológicamente distintas del Perú. Arch Argent Pediatr 2010; 108: 516-23.

18. Mc Intosh K. Community-Acquired Pneumonia in Children. N Engl J Med 2002; 346: 429-37.

19. Moreno L, Krishnan J, Durán P. Ferrero F. Development and validation of a clinical prediction rule to distinguish bacterial from viral pneumonia in children. Pediatr Pulmonol 2006; 41: 33 I-7.

20. Harris M, Clarck J, Coote N, et al. British Thoracic Society guidelines for the management of community acquired pneumonia in children: update 20 I I. Tórax 20 I I; 66: iil -ii23.

21. Peltola V, Mertsola J, Ruuskanen O. Comparison of total white blood cell count and serum C-reactive protein levels in confirmed bacterial and viral infections. J Pediatr 2006; 149: 721-4.

22. Tabain I, Ljubin-Sternak S, Cepin-Bogović J, et al. Adenovirus 
respiratory infections in hospitalized children: clinical findings in relation to species and serotypes. Pediatr Infect Dis J 2012; 31 : 680-4.

23. Chen SP, Huang YC, Chiu CH, et al. Clinical features of radiologically confirmed pneumonia due to adenovirus in children. J Clin Virol 2013; 56: 7.

24. Virkki, TJ, Rakalainen $H$, Svedstron $E$, et al. Differentiation of bacterial and viral pneumonia in children. Thorax 2002; 57: 43841.

25. Martín A, Alfayate D, Couceiro J, García M, Korta J. Etiología y diagnóstico de la neumonía adquirida en la comunidad y sus formas complicadas. Anales de Pediatría 20 12; 76: 162 el-18.

26. Van der Meer $\mathrm{V}$, Neven AK, van den Broek PJ, Assendelft WJ. Diagnostic value of $C$ reactive protein in infections of the lower respiratory tract: systematic review. BMJ 2005; 331: 26.

27. Flood RG, Badik J, Aronoff SC. The utility of serum C-reactive protein in differentiating bacterial from nonbacterial pneumonia in children: a meta-analysis of I 230 children. Pediatr Infect Dis J 2008; 27: 95-9.

28. Moulin F, Raymon J, Larrt M, et al. Procalcitonin in childen admited to hospital with community adquitid pneumonía. Arch Dis Child 2001; 84: 334-9.

29. Niederman MS. Biological markers to determine eligibility in trials for community-acquired pneumonia: a focus on procalcitonin. Clin Infect Dis 2008; 47 Suppl 3: SI27-32.

30. Don M, Valent F, Korppi M, Canciani M. Differentiation of bacterial and viral community-acquired pneumonia in children. Pediatr Intern 2009; 51: 91-6.

31. Lee JY, Hwang SJ, Shim JW, Jung HL, Park MS, Woo HY, et al. Clinical significance of serum procalcitonin in patients with community-acquired lobar pneumonia. Korean J Lab Med 20 I0; 30: $406-13$.

32. Toikka P, Irjala K, Juven T, Virkki R, Mertsola J, Leinonen $M$, et al. Serum procalcitonin, $\mathrm{C}$-reactive protein and interleukin-6 for distinguishing bacterial and viral pneumonia in children. Pediatr Infect Dis J 2000; 19: 598-602.

33. Ruvinsky R. Balanzt AM. Neumonías bacterianas y virales. En: Infecciones respiratorias en niños. Washington. DC. Organización Panamericana de la Salud - Organización Mundial de la Salud 1997 : 215-49.

34. Slverman M, Stratton D, Diallo A, et al. Diagnostic of acute bacterial pneumonia in Nigerian Children. Value of needle aspiration of lung of counter current inmunoelectrophoresis. Arch Dis Child 1977; 52: 925-31.

35. Fletcher M, Leeming J, Cartwright K, Finn A. Childhood empyema: limited potential impact of 7-valent pneumococcal conjugate vaccine. Pediatr Infect Dis J 2006; 25: 559-60.

36. Rovida F, Percivalle E, Zavattoni M, Torsellini M, Sarasini A, Campanini G, et al. Monoclonal antibodies versus reverse transcription-PCR for detection of respiratory viruses in a patient population with respiratory tract infections admitted to hospital. J Med Virol 2005; 75: 336-47.

37. Johansson N, Kalin M, Tiveljung-Lindell A, Giske CG, Hedlund J. Etiology of community-acquired pneumonia: increased microbiological yield with new diagnostic methods. Clin Infect Dis 2010; 50: 202-9.

38. Gadsby NJ, Hardie A, Claas EC, Templeton KE. Comparison of the Luminex Respiratory Virus Panel fast assay with in-house real-time PCR for respiratory viral infection diagnosis. J Clin Microbiol 20 I0; 48: 2213-6.

39. Beersma MF, Dirven K, van Dam AP, Templeton KE, Claas EC, Goossens H. Evaluation of 12 commercial tests and the complement fixation test for Mycoplasma pneumoniae-specific immunoglobulin $\mathrm{G}(\operatorname{lgG})$ and $\lg M$ antibodies, with PCR used as the "gold standard". J Clin Microbiol 2005; 43: 2277-85.

40. Stralin K. Usefulness of aetiological tests for guiding antibiotic therapy in community-acquired pneumonia. Int J Antimicrob Agents 2008; 31: 3-।1.

4l. Swingler $\mathrm{GH}$. Radiologic differentiation between bacterial and viral lower respiratory infection in children: A systematic literature review. Clin Pediatric 2000; 39: 627-33.

42. Marks MI, Klein JO. Bacterial infections of the respiratory tract. En: Feigin RD, Cherry JD, editors. Infections diseases of the fetus and newborn infants. Philadelphia: WB Saunders; 1995: 89I-908.

43. Korppi M, Kiekara O, Heiskanen-Kosma T, Soimaakallio S. Comparison of radiological findings and microbial etiology of childhood pneumonia. Acta Paediatr 1993; 82: 360-3.

44. Khamapirad T, Glezen P. Clinical and radiographic assessment of acute lower respiratory tract disease in infants and in children. Semin Respir Infect 1987; 2: 130-44.

45. MacFarlane J, Rose D. Radiographic features of staphylococcal pneumonia in adults and children. Thorax 1996; 51: 539-40.

46. Jaffe A, Balfour-Lyn IM. Management of empyema in children. Pediatr Pulmonol 2005; 40: |48-56.

47. McLoud TC, Flower CD. Imaging the pleura: sonography, CT and MR imaging. AJR Am J Roentgenol 199|; I 56: I | 45-53.

48. Yang PC, Luh KT, Chang DB, Wu HD, Yu C], Kuo SH. Value of sonography in determining the nature of pleural effusions: analysis of 320 cases. Am J Roentgenol 1992; 159: 29-33.

49. Rammath RR, Heller RM, Ben-Ami, et al. Implications of early sonographic evaluation of parapneumonic effusions in children with pneumonia. Pediatrics 1998; 101:68-71. 